ARTIGO

Recebido em: 07/12/2017

Aceito em:

$02 / 10 / 2018$

\title{
Mediação cultural e bibliotecas: perspectivas conceituais na Ciência da Informação no Brasil
}

\author{
Cultural mediation and libraries: conceptual perspectives in the \\ Science of Information in Brazil
}

\author{
Alessandro RASTELI (alessandrorasteli@yahoo.com.br)*

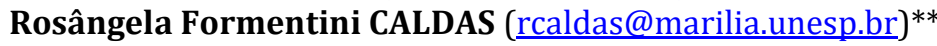 \\ * Doutorando em Ciência da Informação pela Universidade Estadual Paulista - Júlio de Mesquita \\ Filho/Marília. \\ ** Professora doutora da Universidade Estadual Paulista - Júlio de Mesquita Filho/Marília e do \\ Programa de Pós-graduação em Ciência da Informação - PPGCI.
}

\begin{abstract}
Resumo
Apresenta as perspectivas conceituais sobre a mediação cultural em bibliotecas na literatura científica da Ciência da Informação no Brasil. Explora a Base de Dados de Periódicos em Ciência da Informação (BRAPCI), a Biblioteca Digital Brasileira de Teses e Dissertações (IBICT), os Anais do Encontro Nacional de Pesquisa e Pós-Graduação em Ciência da Informação (BENANCIB), o Portal de Periódicos CAPES/MEC e a Library and Information Science Abstracts (LISA). A metodologia constituiu-se em pesquisa de natureza qualitativa, de tipo bibliográfica e descritiva. Pretende-se colaborar e fomentar o debate epistemológico sobre a mediação cultural nas áreas da Ciência da Informação e da Biblioteconomia em âmbito brasileiro. Evidencia-se a mediação cultural como um campo amplo, complexo e que se abre para diversas instâncias, estudos e indagações em diferentes espaços e perspectivas. Em decorrência, várias pesquisas têm focado a mediação cultural sob o viés de perspectivas conceituais diversas destacando-se paradigmas como a construção de sentidos, apropriação cultural, negociação cultural, protagonismo cultural e os dispositivos. Palavras-chave: Mediação Cultural. Ciência da Informação. Bibliotecas; Cultura.
\end{abstract}

\begin{abstract}
It presents the conceptual perspectives on cultural mediation in libraries in the scientific production of Information Science in Brazil. It explores the Database of Periodicals in Information Science (BRAPCI), the Brazilian Digital Library of Theses and Dissertations (IBICT), the Annals of the National Meeting of Research and Graduate in Information Science (BENANCIB), the Portal of Periodicals CAPES / MEC and the Library and Information Science Abstracts (LISA). The methodology consisted of research of a qualitative nature, of a bibliographic and descriptive type. It is intended to collaborate and foster the epistemological debate on cultural mediation in the areas of Information Science and Librarianship in Brazil. Cultural mediation is seen as a broad, complex field that opens up to various instances, studies and inquiries in different spaces and perspectives. As a result, several researches have focused on cultural mediation under the bias of diverse conceptual perspectives highlighting paradigms such as the construction of meanings, cultural appropriation, cultural negotiation, cultural protagonism and devices.
\end{abstract}

Keywords: Cultural Mediation. Information Science. Libraries; Culture.

v. 24, n. 54,2019

p. 01-13

ISSN 1518-2924

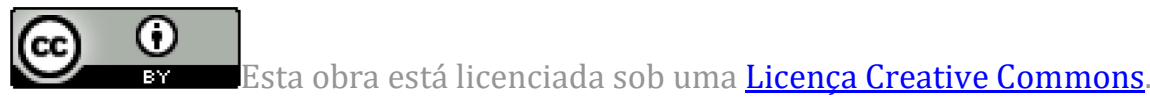




\section{INTRODUÇÃO}

Ao refletir sobre a dimensão da cultura e as bibliotecas, exaltam-se o papel e o poder que esses equipamentos culturais e informacionais possuem para transformarem as comunidades ${ }^{1}$ em que estão inseridos.

Yúdice (2004) concorda que o século XXI marca a passagem da cultura mercadoria para a cultura-recurso. Esse pensamento fundamenta-se na ideia de que a cultura está sendo invocada para resolver problemas, pensada como instrumento para a cidadania e promoção e resgate das identidades coletivas.

A noção de cultura como desenvolvimento está voltada, prioritariamente, para a constituição de indivíduos alfabetizados, letrados, criadores, livres e críticos da realidade que os circundam.

Numa realidade opressora, como a que se vive no Brasil, aliar o trabalho com a cultura na perspectiva de ação libertadora, segundo Freire (1981) resultaria numa inserção crítica de transformação social.

As bibliotecas podem ser participantes no processo de transformação de suas comunidades, onde a leitura, a escrita e demais atividades culturais despontariam as consciências críticas perante as estruturas de dominação.

Tem-se, assim, a percepção ampla do papel da cultura como fator de desenvolvimento econômico, direito do cidadão, instrumentos de inclusão social e ação integradora com potencial transformador.

Entretanto, ainda hoje, diversos segmentos e profissionais desconhecem ou ignoram o papel dos equipamentos informacionais e culturais como auxiliadores na construção do desenvolvimento social.

Coelho (2012) exprime que esses profissionais são formados ou se formam sem jamais terem aberto um livro de antropologia cultural, turismo cultural, cooperação cultural internacional e desenvolvimento humano e econômico, sustentável ou não.

Barros (2003) entende o desenvolvimento social como o avanço do conhecimento, valor humano fundamental alcançado por meio da capacidade de cidadãos bem informados.

Essa concepção leva em consideração o desenvolvimento tanto na dimensão política ou educativa quanto na cultural, atribuindo à informação papel fundamental nos processos mediadores.

Retrospectivamente, alguns estudos da mediação na Ciência da Informação no Brasil rompem no final da década de 1990, quando foi possível visualizar a publicação de Oddone (1998) acerca das transformações que vinham ocorrendo no papel do profissional bibliotecário, onde novas perspectivas e novos paradigmas do trabalho biblioteconômico acarretavam a emergência de uma nova denominação: a do bibliotecário como mediador.

Em sua eloquência, a autora destacou a mediação sob a perspectiva da teoria construtivista sócio histórica de Vygotsky (1991), indicando que a construção do conhecimento ocorre sempre numa situação de dialogicidade e subjetividade. A interação dialógica entre sujeito e objeto, entre sujeito e meio, é mediada tanto por funções e representações simbólicas como pela ação de outros (ODDONE, 1998).

Na perspectiva histórico-cultural de Vygotsky (1991), a mediação assume grande relevância no desenvolvimento humano, uma vez que é através de outros e dos signos (cultura) que os sujeitos estabelecem relações com os objetos de conhecimento. A mediação pelo outro e pelo signo caracterizam, portanto, a atividade cognitiva.

Na Ciência da Informação, os olhares para o núcleo epistemológico da mediação cultural começaram a ganhar força no início do século XXI destacando-se os trabalhos de Almeida (2007); Perrotti e Pieruccini (2007; 2014); Crippa (2008); Paschoal (2009); Gomes (2010); Oliveira (2014); Perrotti (2016); Lima (2016) e Rasteli e Caldas (2017).

Ainda que se perceba um avanço progressivo na produção científica sobre a mediação cultural, Perrotti (2016) diz que definir mediação cultural é uma tarefa que se encontra ainda em processo e não se pode afirmar que, apesar de avanços significativos, já trata-se de uma noção dotada de estabilidade, referindo-se a realidades e/ou fenômenos tomados num mesmo e preciso sentido.

${ }^{1} \mathrm{O}$ termo "comunidade" é utilizado para os mais diversos grupos, porém, aqui seu sentido refere-se a um determinado conjunto de pessoas que têm uma vida partilhada em um espaço comum. 
Todavia, empreender reflexões e debates em torno do conceito de mediação cultural, torna-se um exercício necessário, já que ela se apresenta como categoria, não só cada vez mais presente no país e no mundo, como promissora à análise de questões culturais próprias da contemporaneidade, embora não exclusivamente dela (PERROTTI, 2016).

Evidencia-se a mediação cultural como um campo amplo, complexo e que se abre para diversas instâncias, estudos e indagações em diferentes espaços e perspectivas. Em decorrência, várias pesquisas têm focado a mediação cultural sob o viés de perspectivas conceituais diversas destacando-se paradigmas como a construção de sentidos, apropriação cultural, negociação cultural, protagonismo cultural e os dispositivos.

Em vista disso, o objetivo recai em descrever as perspectivas conceituais sobre a mediação cultural em bibliotecas na literatura científica da Ciência da Informação no Brasil.

Pretende-se, desse modo, colaborar e fomentar o debate epistemológico sobre a mediação cultural nas áreas da Ciência da Informação e Biblioteconomia em âmbito brasileiro.

\section{PROCEDIMENTOS METODOLÓGICOS}

A descrição das técnicas utilizadas na pesquisa qualitativa é de suma relevância para o entendimento do complexo processo interpretativo, que esse tipo de pesquisa requer, bem como para iluminar a realização de novos estudos qualitativos, já que contribui com o aperfeiçoamento da aplicação desta metodologia, dizem Souza, Kantorski e Luis (2011).

Portanto, a pesquisa é de natureza qualitativa, de tipo bibliográfica e descritiva. A descrição dos conceitos sobre a mediação cultural na Ciência da Informação no Brasil e a mediação cultural em bibliotecas derivaram-se de uma busca bibliográfica em suportes impressos (livros) e digitais (e-books, bases de dados, artigos científicos, teses, dissertações e anais de eventos) envolvendo as seguintes palavras-chave: <cultura>, <informação>, $<$ mediação $>$, <mediação cultural $>$, <mediação cultural em bibliotecas $>$.

As fontes bibliográficas utilizadas constituíram-se das seguintes bases de dados: Base de Dados de Periódicos em Ciência da Informação (BRAPCI), Biblioteca Digital Brasileira de Teses e Dissertações (BDTD-IBICT), Anais do Encontro Nacional de Pesquisa em Ciência da Informação (BENANCIB), Portal de Periódicos CAPES/MEC e Library and Information Science Abstracts (LISA).

Para a interpretação dos documentos selecionados, foi realizada uma revisão de literatura minuciosa, a fim de se analisar e descrever os conceitos emitidos na literatura da Ciência da Informação para a mediação cultural.

Destaca-se que este estudo ganha maior expressividade quando se observa o pequeno montante de pesquisas na área de Ciência da Informação relativas às bibliotecas, cultura e artes, ao mesmo tempo em que se percebe a centralidade da cultura nos processos mediadores nos equipamentos de cultura e informação.

\section{MEDIAÇÃo CULTURAL E A CIÊNCIA DA INFORMAÇÃo}

Por muito tempo, a tendência na Ciência da Informação em relação ao seu objeto de pesquisa (informação) esteve atrelada apenas às informações científicas e ao conhecimento registrado, portanto. É o que também argumenta Almeida Júnior (2009) ao mencionar que para muitos pesquisadores da área a informação registrada ainda é o único objeto aceito e pesquisado.

Mostafa (2012) alude que durante a década de 1990, com a crítica ao fechamento da Ciência da Informação e da categoria informação, passou-se a mencionar sobre a mediação cultural e a entender o conhecimento também artístico ou cultural e não apenas informacional.

Assim como a área da educação desenvolveu estudos socioculturais na teorização de Vygotsky e as ciências sociais como um todo se apropriava dos Estudos Culturais ingleses, principalmente via Stuart Hall, a Ciência da Informação abrigou o tema das mediações culturais para pensar outros contextos e práticas de produção e circulação do conhecimento (MOSTAFA, 2012).

Nesse prospecto, por inspiração nos estudos de comunicação que se fortaleceram ao longo dos anos 1960, surgiram as nomenclaturas mediação cultural e o mediador cultural, em contraposição aos termos ação cultural e agente cultural (COELHO, 2012). 
O quadro abaixo mostra a ocorrência histórica das expressões: animação cultural, ação cultural e mediação cultural.

Quadro 1 - Evolução histórica dos termos: animador, agente e mediador cultural

\begin{tabular}{|l|l|l|}
\hline \multicolumn{1}{|c|}{ Termo } & \multicolumn{1}{c|}{ Local } & \multicolumn{1}{c|}{ Período/Surgimento } \\
\hline Animação Cultural/Animador Cultural & França & Século XIX \\
\hline Animação Cultural e Bibliotecas & França & Século XX \\
\hline Ação Cultural/Agente Cultural & França & Século XX (1960; 1970) \\
\hline $\begin{array}{l}\text { Animação Cultural e Bibliotecas/Animador } \\
\text { Cultural e Animador da Leitura }\end{array}$ & Brasil & Século XX (1980) \\
\hline Ação Cultural e Bibliotecas/Agente Cultural & Brasil & Século XX (1980) \\
\hline Mediação Cultural/Mediador Cultural & França & Século XX \\
\hline Mediação Cultural e Bibliotecas & França & Século XX (1990) \\
\hline Mediação Cultural & Brasil & Século XX (1990) \\
\hline Mediação Cultural e Bibliotecas & Brasil & Século XXI \\
\hline
\end{tabular}

Fonte: Elaborado a partir de Coelho (2012); Sperry (1987) e Almeida (1987).

A animação cultural apareceu na França em meados do século XIX.

Coelho (2012, p. 15) diz que "desde o início do século XX (e, na França, antes ainda), corrente era a ideia da animação cultural". No Brasil, a animação cultural e a biblioteca apareceram nos discursos científicos da Biblioteconomia no decorrer dos anos de 1980. Sperry (1987, p. 14, grifo da autora) dizia que:
Algumas técnicas estrangeiras, chegadas há poucos anos no Brasil, já constituem disciplina dos cursos de graduação e de pós- graduação, como a Informática, a Administração de Sistemas e o Marketing da Informação. Outras, como a ANIMAÇÃO CULTURAL EM BIBLIOTECAS, somente agora começam a ser observadas como conhecimento, pois sempre foram mais objeto de experiências profissionais do que frutos de estudos e pesquisas.

Ainda na década de 1980, alguns autores suscitaram o bibliotecário como um agente cultural. Almeida (1987) refere-se que a ideia de animação cultural passou a circular entre os bibliotecários justamente em um momento de crise ao perceber-se que a biblioteca tinha de mudar, arejar e permitir a entrada de energia nova, combatendo a situação de desgaste entrópico em que se encontrava.

Já a ideia de ação cultural chegou aos espaços das bibliotecas tomando como referência Francis Jeanson (1973), em sua obra L'action culturelle dans la cité, assumindo-se que o processo de ação cultural se resume na criação ou organização das condições necessárias para que as pessoas inventem seus próprios fins e tornem-se assim, sujeitos da cultura e não seus objetos (COELHO, 2012).

Durante as décadas de 1980 e 90, Coelho (1986; 1989) foi um dos poucos autores brasileiros a discutir sobre os conceitos de animação cultural e ação cultural. Também se deve a Coelho (1997) a elaboração da primeira definição para mediação cultural apresentando-a no verbete do Dicionário crítico de política cultural:

Processos de diferente natureza cuja meta é promover a aproximação entre indivíduos e obras de cultura e arte. Essa aproximação é feita com o objetivo de facilitar a compreensão da obra, seu conhecimento sensível e intelectual - com o que se desenvolvem apreciadores ou espectadores, na busca da formação de públicos para a cultura - ou de iniciar esses indivíduos e coletividades na prática efetiva de uma determinada atividade cultural. [...] Os diferentes níveis em que essas atividades podem ser desenvolvidas caracterizam modos diversos da mediação cultural, como a ação cultural, a animação cultural e a fabricação cultural (COELHO, 1997, p. 247, grifo do autor). 
De acordo com Coelho (1997), a mediação cultural constitui-se em um processo que se desenvolve através de ações diversas como a animação, a ação e a fabricação cultural. Nota-se, também, que no conceito forjado pelo autor, a mediação cultural é analisada como processos com objetivos de promover a aproximação entre o público e os objetos culturais.

Nas lógicas contemporâneas, o conceito de mediação ganha destaque por sua centralidade nas interações sociais e apropriações simbólicas, passando a ser compreendida por Gomes (2014) como uma ação inerente a todo fazer do profissional da informação, dando maior relevo à responsabilidade social desse agente mediador e também dos ambientes informacionais enquanto espaços de construção de sentidos.

A noção de mediação veio se transformando nos últimos anos, "passando da ideia de transmissão unilinear, concebida nas teorias clássicas e alicerçada na figura de um mediador ou de uma mídia, a um processo onde intervêm diferentes agentes técnicos, sociais e culturais" (MARTELETO; COUZINET, 2013, p. 3).

Essa prospecção também é compartilhada por Perrotti e Pieruccini (2014) ao dizerem que a mediação cultural recobre um conjunto multiforme de práticas culturais, considerando-se uma gama diversificada de manifestações diferenciadas. Nesse sentido, o conceito de mediação cultural se constitui como um conjunto de elementos de diferentes ordens (material, relacional, semiológica) que se interpõem e atuam nos processos de significação (PERROTTI; PIERUCCINI, 2007).

Nota-se que a mediação efetiva-se por meio dos fluxos comunicacionais e informacionais, envolvendo ações, linguagens, suportes, objetos e sujeitos em relações dinâmicas, que para Paschoal (2009, p. 22, grifo da autora), "constituem-se e constituem atividades discursivas. Eles dialogam, narram, negociam simbolicamente estratégias e criam performances. Eles articulam e são eles mesmos dispositivos".

Perrotti e Pieruccini (2007, p. 83-84) dizem que o conceito de mediação cultural é correlato ao de dispositivo:

tomamos em nossos trabalhos a mediação cultural como categoria intrínseca aos processos de significação, portanto, essencial, condição que leva a considerar os elementos que constituem seus processos não simplesmente como ferramentas, mas como signos, portadores de sentidos, agregados à economia das significações. [...] Nesse sentido, os dispositivos informacionais são dispositivos de mediação e estão carregados de conceitos e significados. Necessitam, portanto, ser considerados além de suas dimensões funcionais. São processos simbólicos, discursos. Contam. Narram.

Nessa vertente, o conceito de mediação cultural estabelece-se como um conjunto de elementos de diferentes ordens que se interpõem e atuam nos processos de significação no vasto território da cultura.

Ao adotar a negociação cultural como categoria teórico-metodológica orientadora de processos de mediação voltados à apropriação da cultura escrita, Oliveira $(2014$, p. 226, grifo da autora) diz que:

O conceito de negociação cultural revela uma dimensão operatória capaz de lidar com situações concretas e simbólicas de conflito, ao mesmo tempo em que parece apontar caminhos promissores, tendo em vista uma sociedade multifacetada, "polifônica", [...]. Nesse sentido, ele refere-se, também, a um valor que, além de procedimentos, demanda atitudes, modos de ser e de se relacionar.

Assim, nos dispositivos estudados por Oliveira (2014, p. 226), a apropriação da cultura escrita foi sendo construída "por meio de negociações entre leitores, textos, seus diferentes suportes e sentidos, e a trama das mediações em sua diversidade e dinamicidade".

Na acepção de Oliveira (2014), a negociação se diferencia de dominação e de conciliação ao trazer embutido um processo dinâmico de busca de acordo, sem submissões, 
mas de reconhecimento do espaço do outro - e não um processo finalizado e/ou com a supremacia de um sobre o outro.

No destaque à negociação e apropriação cultural, Perrotti e Pieruccini (2007, p. 74), argumentam que a apropriação é ação afirmativa com e sobre significados negociados que "[...] diferencia e constitui os negociadores como sujeitos da cultura, protagonistas, cidadãos". Além disso, apropriar-se de informação e cultura é ato próprio de protagonistas, categoria que no âmbito da educação e cultura se distinguem das de usuários e de consumidores culturais [...]" (PERROTTI; PIERUCCINI, 2007, p. 77).

Nesse âmbito, a mediação cultural para Lima e Perrotti (2016) é vista como atividade que visa proporcionar igualdade de oportunidades e condições para que as pessoas estejam inseridas como protagonistas no percurso cultural e, assim, em processos dinâmicos de apropriação, possam ressignificar e reconstruir os bens culturais, bem como inventá-los, defini-los e renová-los.

Lessa e Gomes (2017) ao refletirem sobre a mediação cultural e suas implicações sociais e conceituais, situam a biblioteca, em especial a pública, como espaço social dessa ação ao realizar a mediação da informação. Ainda, ao discutir as possibilidades de atuação da biblioteca pública, as autoras apontam:

seu potencial transformador ao representar um espaço de encontro e de diálogo em meio a diversidade cultural e de dispositivos tecnológicos, que diversificam o modo de produção e circulação dos bens culturais, informação, que reflitam a diversidade cultural e que oferte o acesso, o encontro, o diálogo, tanto no espaço virtual quanto no seu espaço físico, proporcionando o conforto que gera no usuário o sentimento de pertença, potencializador da sua condição de protagonista social (LESSA; GOMES, 2017, p. 35-36).

Ambiciona-se que as bibliotecas, além da prestação de seus serviços tradicionais à comunidade, possam se reafirmar como instituições ativas nos processos de mediação e de construção social, cultural e histórica dos espaços onde estão inseridas.

Lessa e Gomes (2017) nos chamam a atenção para a demanda por um arcabouço teórico da mediação cultural na Ciência da Informação e na Biblioteconomia para a formação do mediador cultural que protagonize, junto a um público, ações que modifiquem e ressignifiquem a cultura e a si próprio, por meio da negociação de sentidos.

Desse modo, a mediação cultural pode ser entendida como uma construção e representação dos processos sociais, culturais, artísticos e informacionais, cuja interação com indivíduos e/ou grupos, pode promover significados e sentidos à realidade a partir de um conjunto de atividades pensadas e constituídas coletiva e dialogicamente.

Nessa perspectiva, podemos perceber que nas bibliotecas os dispositivos referem-se às linguagens informacionais, às técnicas (mediações implícitas), aos suportes informacionais (papel, digital) e aos produtos culturais, cujas instâncias são pensadas como portadores de sentidos, o que ressalta suas possibilidades discursivas nos atos de significação cultural e que influem nos processos de apropriação cultural.

A mediação cultural, nesses termos, é a atividade que visa proporcionar igualdade de oportunidades e condições para que as pessoas estejam inseridas como protagonistas no percurso cultural e, assim, em processos dinâmicos de apropriação possam ressignificar e reconstruir os bens culturais, bem como inventá-los, defini-los e renová-los (LIMA, 2016, p. 173).

Visualizamos, assim, a mediação cultural em bibliotecas como processos que possibilitam a elaboração de sentidos com potencial para a construção de interações, apropriações e conhecimentos.

Os conceitos apresentados circunscrevendo a mediação cultural apoiam-se na noção de mediação como ação, interação, interferência, dialogicidade e construção de sentidos por intermédio da negociação cultural.

Percebemos a mediação cultural como processo social, que se expande em distintos olhares e em múltiplas áreas do saber dada a sua complexidade e alcance multidisciplinar. 


\section{MEDIAÇÃO CULTURAL E BIBLIOTECAS}

Observa-se um aumento em pesquisas circunscrevendo a mediação cultural em bibliotecas. Em vista disso, foi elaborada uma amostragem de trabalhos que abordam a temática, descritos no quadro abaixo.

Quadro 2 - Produção bibliográfica sobre a mediação cultural em bibliotecas

\begin{tabular}{|l|l|l|}
\hline Autor & Título & Tipologia \\
\hline Lessa; Gomes (2017) & $\begin{array}{l}\text { A biblioteca pública como um empório } \\
\text { de ideias: evidências do seu lugar na } \\
\text { sociedade contemporânea }\end{array}$ & Artigo de Periódico \\
\hline Rasteli; Caldas (2017) & $\begin{array}{l}\text { Percepções sobre a mediação cultural } \\
\text { em bibliotecas na literatura nacional e } \\
\text { estrangeira }\end{array}$ & Artigo de Periódico \\
\hline Silva; Santos Neto (2017) & $\begin{array}{l}\text { Práticas de mediação cultural nas } \\
\text { bibliotecas públicas municipais de } \\
\text { Londrina/PR }\end{array}$ & Artigo de Periódico \\
\hline Lima (2016) & $\begin{array}{l}\text { O bibliotecário como mediador } \\
\text { cultural: concepções e desafios à sua } \\
\text { formação }\end{array}$ & Artigo de Periódico \\
\hline Lima; Perrotti (2016) & $\begin{array}{l}\text { Bibliotecário: um mediador cultural } \\
\text { para a apropriação cultural }\end{array}$ & Tese de Doutorado \\
\hline Dias (2015) & $\begin{array}{l}\text { Bibliotecas como livrarias? Repensando } \\
\text { fronteiras entre instituições culturais } \\
\text { na contemporaneidade }\end{array}$ & Artigo de Periódico \\
\hline Salcedo; Alves (2014) & $\begin{array}{l}\text { A mediação cultural na biblioteca } \\
\text { escolar }\end{array}$ & Artigo de Periódico \\
\hline Caires (2014) & $\begin{array}{l}\text { Biblioteca na educação: práticas } \\
\text { colaborativas e apropriação cultural }\end{array}$ & $\begin{array}{l}\text { Trabalho } \\
\text { Apresentado em } \\
\text { Evento }\end{array}$ \\
\hline Rasteli; Cavalcante (2014) & $\begin{array}{l}\text { Mediação cultural e apropriação da } \\
\text { informação em bibliotecas públicas }\end{array}$ & Artigo de Periódico \\
\hline Souza; Santos (2012) & $\begin{array}{l}\text { Educação para o patrimônio: mediação } \\
\text { cultural na perspectiva dos museus e } \\
\text { bibliotecas: uma experiência }\end{array}$ & Artigo de Periódico \\
\hline Flusser (1980) & $\begin{array}{l}\text { Uma biblioteca verdadeiramente } \\
\text { pública }\end{array}$ & Artigo de Periódico \\
\hline
\end{tabular}

Fonte: Elaboração própria.

Visualiza-se uma maior concentração acerca de trabalhos que abordam a mediação cultural e as bibliotecas em pesquisas publicadas em periódicos. É possível constatar, através de levantamento bibliográfico realizado na Base de Dados de Periódicos em Ciência da Informação (BRAPCI), que o termo mediação aparece na literatura especializada da Biblioteconomia em 1980 por intermédio de Victor Flusser.

Flusser (1980) discutiu sobre a ação cultural na biblioteca pública com o propósito de estabelecer vínculos com os marginalizados, no qual o autor se refere como o "não público", ou seja, aqueles que não têm acesso às bibliotecas e menos ainda à produção cultural.

Ao traçar as diferenças entre a biblioteca pública tradicional e a biblioteca-ação cultural, Flusser (1980) propôs, através da mediação cultural, a análise com criticidade da herança cultural, observando a dimensão criativa e dessa forma respondendo as reais necessidades da comunidade. Nesse intento, o animador-bibliotecário não ficaria à disposição da comunidade, mas ao contrário faria parte dela.

Para Flusser (1980, p. 137), uma biblioteca verdadeiramente pública, "desenvolve com um não-público as dimensões de criação e mediação de forma integrada, não deverá se restringir somente à cultura literária". Sua vocação é a de vir ser o centro cultural de sua comunidade e um instrumento de libertação.

Em direção às ações libertadoras, Flusser (1980) menciona uma política cultural libertadora, com o intuito de dar a palavra aos sujeitos, numa perspectiva de criação, recriação, de decisão e escolhas. 
Ao evidenciar a biblioteca escolar, Salcedo e Alves (2014) afirmam que a biblioteca pode ser considerada como um dispositivo cultural e que nesse caso:

auxiliam no ato de mediar. Dão apoio ao mediador, sendo o dispositivo físico ou virtual. A palavra "dispositivo" está ligada à ação de dispor, ou seja, colocar em certa ordem. E é esse o papel desses ambientes culturais, ajustar e unir os componentes do ciclo da mediação: mediador - objeto - mediado (SALCEDO; ALVES, 2014, p. 84, grifo dos autores).

Em referência aos trabalhos de Perrotti e Pieruccini (2007), Rasteli e Cavalcante (2014) também verificam as bibliotecas públicas como dispositivos produtores de sentidos. Reconhecer a existência de dispositivos, a exemplo das bibliotecas, como produtores de sentido, é também verificar as ações de mediação cultural como atos de significação, vivenciados com modos de interação entre diferentes experiências culturais (RASTELI; CAVALCANTE, 2014).

Dessa maneira, o mediador cultural é tido como o articulador entre os bens culturais saberes e objetos simbólicos - e os sujeitos por meio de dispositivos ou recursos para o acesso, criação e apropriação de bens culturais simbólicos.

No percurso constitutivo das bibliotecas evidenciam-se três paradigmas norteadores da sua existência: o paradigma da conservação cultural, da difusão cultural e da apropriação cultural (GOMES, 2014; PERROTTI, 2017).

O primeiro paradigma diz respeito ao paradigma da conservação ou da preservação, baseado em ideais antigos e medievais, cujas instituições estiveram focadas em objetos conservacionistas.

Nos tempos modernos, difundir cultura era um princípio essencial, intrínseco à construção da nova ordem histórica que sucedia à ordem medieval, alicerçadas nos ideais do Iluminismo, o que possibilitou o desenvolvimento do segundo paradigma: o da difusão cultural (PERROTTI, 2017).

$\mathrm{Na}$ contemporaneidade, existe um pleito por um novo paradigma dados os limites dos anteriores para responder as necessidades próprias de nossa época: o paradigma da apropriação cultural em que a biblioteca é concebida como um espaço em que o sujeito não apenas assimila, mas se apropria da cultura.

Nesse sentido, a biblioteca passa a ter que reorganizar seus processos em todos os níveis, já que não se trata mais de apenas ofertar, dar acesso aos bens culturais, transmitir repertórios, mas sim de mediá-los, de reconhecê-los e de atuar no sentido de que eles não só circulem, mas sejam apropriados por públicos diferentes, heterogêneos e em busca não somente de informações, mas sobretudo de expressão e afirmação cultural (PERROTTI; PIERUCCINI, 2007).

Ao destacar a apropriação cultural como resultado dos processos de mediação distanciam-se as ideias de conservação e de difusão aproximando-se da noção de participação ativa da comunidade nos modos culturais, posicionando os sujeitos como protagonistas culturais.

Lima e Perrotti (2016) ao interrogar a formação do bibliotecário como mediador cultural, oferecem referências capazes de apontar perspectivas de superação de desafios para a sua formação de mediador cultural comprometido com a apropriação e o protagonismo cultural.

A mediação cultural - termo mais amplo que em nosso entendimento engloba a mediação da informação, por ser a informação um objeto cultural - requer do mediador competências e atitudes de um protagonista cultural, para atuar como tal junto a outros protagonistas, com conhecimentos interdisciplinares e consciência de sua função social (LIMA; PERROTTI, 2016, p. 162).

Lima e Perrotti (2016) chamam a atenção para o trabalho do bibliotecário mediador como um protagonista, atuando com conhecimentos múltiplos e interdisciplinares. 
A mediação cultural, compreendida como atividade criativa e criadora (PERROTTI; PIERUCCINI, 2014), requer dos profissionais, por sua vez, domínio de diferentes saberes e ordens, não apenas operacional e metodológica, mas teórico-epistemológicas.

Do ponto de vista da complexidade cultural em que estamos imersos, o mediador cultural carece de ter domínio tanto de saberes gerais como específicos relativos aos seus objetos e objetivos: a cultura, a informação, as artes e a educação, tomadas, de acordo com Perrotti (2016), em seus múltiplos aspectos operacionais, procedimentais e conceituais.

Na realidade brasileira, caracterizada historicamente por rupturas sociais e culturais, somos impelidos a pensar a mediação cultural em observância às concepções de cultura, às políticas culturais, às regulações da cultura e às hegemonias.

O encontro entre bibliotecário e usuário torna a mediação cultural uma ação de compartilhamento simbólico, cuja proposta está em participar, interagir e construir significados, redundando na apropriação cultural.

A aquisição do conhecimento, a partir do contato com as mediações de qualquer modalidade discursiva, representa, portanto, fontes de novas elaborações cognitivas, porque criam processos de internalização (VYGOTSKY, 1991), que se dá pela interação, reflexão e pelo compartilhamento de experiências.

Acredita-se que a mediação cultural pode originar novas formas de conduta, que modificando o comportamento humano edificará consciências críticas, melhorando assim, o diálogo e as condições de vida entre as pessoas da comunidade, o que também pode ser compreendido como uma forma de desenvolvimento humano a partir das experiências culturais.

\section{CONSIDERAÇõES FINAIS}

Entende-se que a mediação cultural se estabelece como fenômeno eminentemente comunicacional e multidisciplinar, observando as contribuições de Vygotsky (1991), quando se entende que a mediação pelo outro e pelo signo caracterizam, portanto, a atividade cognitiva.

O conceito de mediação cultural aponta para as interações sociais e apropriações simbólicas, caracterizando-se como um processo de intersubjetividades, permitindo aos sujeitos interpretar sentidos e gerar novas significações.

Como instância cultural, a mediação é vista em espaços onde os sujeitos produzem e se apropriam de significados nas esferas comunicacionais e informacionais como as bibliotecas.

Correlato ao conceito de mediação cultural, enquanto produção de sentidos, está a definição de cultura fornecida por Coelho (2012) quando diz que a cultura se apresenta sob a forma de diferentes manifestações que integram um vasto e intricado sistema de significações.

Na visão simbólica dos processos culturais, compreende-se que o sujeito através da interação social compartilha os processos de significação cultural com os outros homens, com os objetos, com os artefatos, com as ferramentas, com as técnicas, com os conteúdos informacionais, determinando ao mesmo tempo instâncias dialógicas na comunicação, na linguagem, na apropriação e formação da cultura.

Refletir sobre os conceitos emitidos para a mediação cultural na Ciência da Informação faz-se um empreendimento necessário, uma vez que a construção epistemológica permite a observação, descrição e interpretação dos objetos teóricos e empíricos de uma área do conhecimento, assim como os fenômenos presentes, passados e futuros a eles relacionados.

Todas as bibliotecas são instâncias de mediação entre os sujeitos e o universo cultural. Desse modo, pretende-se que a mediação cultural possa responder aos inúmeros desafios da sociedade atual, tendo em vista a complexidade e a gama de fenômenos que se apresentam, articulando formas de representação social.

O Brasil é um país culturalmente plural. Pelo nosso histórico de dominação colonial, vários costumes, linguagens, dialetos, comportamentos, hábitos, valores e tradições foram sendo herdados, criados e transmitidos, constituindo hoje o que podemos denominar de interculturalismo ou pluralidade cultural na formação do nosso país. 
Aponta-se que cada equipamento cultural possui suas diferenças, suas características e missões. Nesse caso, as ações orientadas pelos mediadores culturais deverão priorizar as bibliotecas como espaços de construção permanente da cultura, cujo potencial está em influenciar, modificar e transformar o modo de vida das pessoas em direção à qualidade de vida e ao desenvolvimento sociocultural.

Os estudos sobre a apropriação cultural assinalam a relevância das ações de mediação, evidenciando as bibliotecas como espaços para favorecer o acesso, à circulação e à produção cultural, privilegiando a dialogia, a interação, o compartilhamento e o debate em torno delas, condições necessárias ao processo de construção do conhecimento e apropriação dos conteúdos, essência da formação de protagonistas sociais e culturais.

O bibliotecário é, portanto, um mediador social que realiza uma ação substantiva e transformadora e não uma ação meramente instrumental e neutra.

Considera-se desse modo, que na realização das atividades culturais, o trabalho do mediador cultural não é neutro, existindo de fato interferências.

Nessa abordagem, vale mencionar que a mediação não pode ser compreendida como neutra, muito menos como uma ponte estática, mas sim, como processo ativo, definido e relacionado com contextos, sujeitos e processos específicos.

\section{REFERÊNCIAS}

ALMEIDA, M. C. B. A ação cultural do bibliotecário: grandeza de um papel e limitações de uma prática. R. bras. Bibliotecon. e Doe., São Paulo, v. 20, n. 1/4, p. 31-8, jan./dez. 1987.

ALMEIDA, M. A. Mediação cultural e da informação: considerações socioculturais e políticas em torno de um conceito. ENCONTRO NACIONAL DE PESQUISA EM CIÊNCIA DA INFORMAÇÃO, 8., 2007, Salvador. Anais eletrônico... Disponível em: http://www.enancib.ppgci.ufba.br/artigos/GT3--212.pdf. Acesso em: 12 jun. 2017.

ALMEIDA JÚNIOR, O. F. de. Mediação da informação e múltiplas linguagens. Pesquisa Brasileira em Ciência da Informação, Brasília, v. 2, n.1, p. 89-103, jan./dez. 2009. Disponível em: http://inseer.ibict.br/ancib/index.php/tpbci/article/view/17/39. Acesso em: 09 ago. 2017.

BARROS, M. H. T. C. Disseminação da informação: entre a teoria e a prática. Marília: s.n., 2003.

CAIRES, F. M. Biblioteca na educação: práticas colaborativas e apropriação cultural. Dissertação (Mestrado em Ciência da Informação) - Escola de Comunicação e Artes, Universidade de São Paulo, 2014. Disponível em: http://www.teses.usp.br/teses/disponiveis/27/27151/tde-20012015-111621/pt-br.php. Acesso em: 28 ago. 2017.

CAUNE, J. Cultura e comunicação: convergências teóricas e lugares de mediação. Trad. Laan Mendes de Barros. São Paulo: Ed. Unesp, 2014.

COELHO, T. Dicionário crítico de política cultural: cultura e imaginário. São Paulo: Iluminuras, 1997.

COELHO, T. Dicionário crítico de política cultural: cultura e imaginário. 2. ed. São Paulo: Iluminuras, 2012.

COELHO, T. Usos da cultura: políticas de ação cultural. Rio de Janeiro: Paz e Terra, 1986. (Educação e comunicação, v. 16)

COELHO, T. 0 que é ação cultural. São Paulo: Brasiliense, 1989. (Coleção primeiros passos, 216). 
CRIPPA, G. Exposições e dispositivos do gênero no espaço público: silêncios da mediação cultural. In: COLÓQUIO MEDIAÇÕES E USOS DE SABERES E INFORMAÇÃO, 1., 2008, Rio de Janeiro. Anais... Rio de Janeiro: Rede MUSSI, 2008. p. 491-506.

CUÉLLAR, J. P. (Org.). Nossa diversidade criadora. Relatório da Comissão Mundial de Cultura e Desenvolvimento. Campinas/Brasília: Papirus/Unesco, 1997.

FLUSSER, V. (1980). Uma biblioteca verdadeiramente pública. Revista da Escola de Biblioteconomia UFMG, v. 9, n. 2, 131-138, 1980. Disponível em:

http://www.brapci.ufpr.br/brapci/repositorio/2011/04/pdf_c8d8abec0f 0016030.pdf. Acesso: 3 de ago. 2017.

FREIRE, P. Ação Cultural para a liberdade: e outros escritos. 5 ed. Rio de Janeiro: Paz e Terra, 1981. (Coleção O Mundo Hoje, 10).

GOMES, H. F. Tendências de pesquisa sobre mediação, circulação e apropriação da informação no Brasil: estudo em periódicos e anais dos ENANCIB (2008-2009). Pesquisa Brasileira Ciência da Informação, Brasília, v.3, n.1, p.85-99, jan./dez., 2010. Disponível em: http://periodicos.ufpb.br/index.php/pbcib/article/view/11997. Acessado em: 20 mai. 2017.

GOMES, H. F. A biblioteca pública e os domínios da memória, da mediação e da identidade social. Perspectivas em Ciência da Informação, v.19, número especial, p.151-163, out./dez. 2014. Disponível em:

http://www.brapci.ufpr.br/brapci/index.php/article/download/32272. Acesso em: 15 jul. 2017.

GRANJA, E. C. Da leitura entre estudantes universitários aos programas de animação cultural: algumas reflexões. R. bras. Bibliotecon. e Doe., São Paulo, v. 20, n.1/4, p. 39-44, jan./dez. 1987.

\section{JEANSON, F. L'action culturelle dans la cite. Paris, Seul, 1973.}

LESSA, B.; GOMES, H. F. A biblioteca pública como um empório de ideias: evidências do seu lugar na sociedade contemporânea. Informação \& Sociedade: estudos, v. 27, n. 1, p. 35-46, 2017. Disponível em: http://www.brapci.ufpr.br/brapci/v/a/23076. Acesso em: 30 ago. 2017.

LIMA, C. B. 0 bibliotecário como mediador cultural: concepções e desafios à sua formação. 2016. 182 f. Tese (Doutorado em Ciência da Informação) - Escola de Comunicações e Artes, Universidade de São Paulo, 2016. Disponível em:

http://www.teses.usp.br/teses/disponiveis/27/27151/tde-26092016-145726/pt-br.php. Acesso em: 3 ago. 2017.

LIMA, C. B.; PERROTTI, E. Bibliotecário: um mediador cultural para a apropriação cultural. Informação@Profissões, v. 5, n. 2, p. 161-180, 2016. Disponível em:

http://www.brapci.ufpr.br/brapci/v/a/22785. Acesso em: 30 ago. 2017.

MARTELETO, R.; COUZINET, V. Mediações e dispositivos de informação e comunicação na apropriação de conhecimentos: elementos conceituais e empíricos a partir de olhares intercruzados. RECIIS - R. Eletr. de Com. Inf. Inov. Saúde. Rio de Janeiro, v.7, n.2, jun., 2013. Disponível em: https://www.reciis.icict.fiocruz.br/index.php/reciis/article/view/450/1104. Acesso em: 27 ago. 2017.

MOSTAFA, S. P. (2012). Conhecimento, informação e meios de transmissão cultural. Informação \& Sociedade.:Est., v. 22, n. 3, p. 95-100, 2012. Disponível em: http://www.ies.ufpb.br/ojs2/index.php/ies/article/view/14993. Acesso em: 12 jun. 2017. 
ODDONE, N. O profissional da informação e a mediação de processos cognitivos: a nova face de um antigo personagem. Informação \& Sociedade: estudos, v. 8, n. 1, p. 1-11, 1998. Disponível em:

http://www.brapci.ufpr.br/brapci/index.php/article/view/0000007651/72932037aa65d0 43f126a32210e36ddc. Acesso em: 20 jul. 2017.

OLIVEIRA, A. L. A negociação cultural: um novo paradigma para a mediação e a apropriação da cultura escrita. 2014. 249 f. Tese (Doutorado em Ciência da Informação) - Escola de Comunicação e Artes, Universidade de São Paulo, São Paulo, 2014. Disponível em: http://www.teses.usp.br/teses/disponiveis/27/27151/tde-16102014-104805/pt-br.php. Acesso em: 03 mai. 2017.

PASCHOAL, S. B. N. Mediação cultural dialógica com crianças e adolescentes: oficinas de leitura e singularização. Dissertação (Mestrado em Ciência da Informação) - Escola de Comunicação e Artes, Universidade de São Paulo, 2009. Disponível em:

http://www.teses.usp.br/teses/disponiveis/27/27151/tde-28102010-103831/pt-br.php. Acesso em: 23 jul. 2017.

PERROTTI, E.; PIERUCCINI, I. Infoeducação: saberes e fazeres da contemporaneidade. In: LARA, M. L. G, FUJINO, A. NORONHA, D. P. (Org.)

Informação e contemporaneidade:

perspectivas. Recife: Néctar, 2007. Disponível em: http://www.pos.eca.usp.br/sites/default/files/file/cienciaInformacao/informacaoContemp oraniedade.pdf. Acesso: 05 jul. 2017.

PERROTTI, E.; PIERUCCINI, I. A mediação cultural como categoria autônoma. Informação Informação, Londrina, v. 19, n. 2, p. 01 - 22, maio./ago. 2014.

http:www.uel.br/revistas/informacao/. Disponível em:

http://www.uel.br/revistas/uel/index.php/informacao/article/view/19992. Acesso em: 25 ago. 2017.

PERROTTI, E. Mediação cultural: além dos procedimentos. In: SALCEDO, D. A. (Org.) Mediação cultural. São Carlos: Pedro \& João Editores, 2016. Disponível em: https://drive.google.com/file/d/0ByZq6ZWinK9pU3RmZ2pJc3FwT2s/view. Acesso em: 23 ago. 2017.

RAMOS, L. B. Centros de cultura, espaços de informação: um estudo sobre a ação do Galpão Cine Horto. Belo Horizonte: Argumentum: 2008.

RASTELI, A.; CAVALCANTE, L. E. Mediação cultural e apropriação da informação em bibliotecas públicas. Encontros Bibli, v.19, n.39, 2014. Disponível em: https://periodicos.ufsc.br/index.php/eb/article/view/1518-2924.2014v19n39p43/26577. Acesso em: 3 ago. 2017.

RASTELI, A.; CALDAS, R. F. Percepções sobre a mediação cultural em bibliotecas na literatura nacional e estrangeira. TransInformação, Campinas, v. 29, n. 2, p.151-161, maio/ago., 2017. Disponível em: http://www.scielo.br/pdf/tinf/v29n2/0103-3786-tinf-29-02-00151.pdf. Acesso em: 03 ago. 2017.

SALCEDO, A. D.; ALVES, R. M. F. A mediação cultural na biblioteca escolar. Biblios, n. 54, p. 82-87, 2014. Disponível em: http://biblios.pitt.edu/. Acesso em: 28 jun. 2017.

SOUZA, J.; KANTORSKI, L. P.; LUIS, M. A. V. Análise documental e observação participante na pesquisa em saúde mental. Revista Baiana de Enfermagem, Salvador, v. 25, n. 2, p. 221228, maio/ago. 2011.

TÉBAR, L. 0 perfil do professor mediador: pedagogia da mediação. Trad. Priscila P. Mota. São Paulo: Editora Senac, 2011. 
TSUPAL, R. Leitura e atividades culturais na biblioteca pública: aspectos teóricos. R. Bibliotecon. Brasília, v. 15, n. 2, p.149- 165, jul./dez. 1987.

VYGOTSKY, L. S. A formação social da mente: o desenvolvimento dos processos psicológicos superiores. 4. ed. São Paulo: Martins Fontes, 1991.

YÚDICE, G. A conveniência da cultura: usos da cultura na era global. Trad. De Marie-Anne Kremer. BH: Editora UFMG; 2004.

Editores do artigo: Enrique Muriel-Torrado, Edgar Bisset Alvarez, Camila Barros 